\title{
Ex Ante Impact Assessment of Reservoir Construction Projects for Different Stakeholders Using Agent-Based Modeling
}

\section{Chakaphon Singto ${ }^{1}$ (D) Martijn de Vries $^{2} \cdot$ Gert Jan Hofstede $^{2} \cdot$ Luuk Fleskens $^{1}$}

Received: 15 April 2020 / Accepted: 12 January 2021/

Published online: 8 February 2021

(c) The Author(s) 2021

\begin{abstract}
Reservoir construction projects are frequently met with fierce opposition. Consequently, to mitigate any potential negative impacts, environmental and social impact assessments are usually mandatory. Stakeholder perspectives are often only implicit in such assessments, and the medium-term effects of mitigating actions are assessed at the aggregate level, which fails to take into account unequal disaggregated impacts. In this paper, we design and apply an agent-based model (ABM) built on stakeholder information to conduct an ex ante assessment of the impact of a reservoir construction project in southern Thailand over a 30-year period for individual agents. We incorporate stakeholders' knowledge into the ABM on the basis of primary data collected during the 2016-2018 period, including workshops with affected farmers to assess their interests and concerns, in-depth interviews with farmers in nearby districts to assess farming behaviors, and the expert opinions of policymakers to assess the relevant regulations and processes. In a case study for which the model was established, the results predict that, overall, farmers will have more farm income if the dam is built. We find that affected people require a standard of living similar to that provided by their previous livelihood as soon as possible after resettlement. By simulating the impacts on individual agents, we conclude that the compensation for relocation offered to affected farmers is not sufficient for sustainable resettlements. Facilitating compensation may increase the speed of project implementation and lead to better outcomes for everyone, including affected communities, whereas failure to reshape the current compensation policy leaves everyone more disadvantaged.
\end{abstract}

Keywords Water resource planning · Dam conflicts $\cdot$ Policymakers $\cdot$ Affected stakeholders · Compensation · Thailand

\section{Introduction}

A development project can benefit some people but negatively impact other groups of stakeholders. Typically, a majority of stakeholders support a project because they expect

Chakaphon Singto

chakaphon.singto@gmail.com

Extended author information available on the last page of the article 
economic benefits. However, some affected stakeholders do not see an equal opportunity for economic benefit sharing, and they anticipate adverse impacts and uncertain long-term livelihood security, as a result of which they oppose the project. Conflicts among stakeholders often lead to a deadlock in finding acceptable solutions, and they preclude adaptations of plans to limit uncertainties.Land acquisitions are commonly implemented to support economic development projects, but the mandated compensation is usually unreasonable, complex, implicit and insufficiently participatory for the affected stakeholders (Ghatak and Mookherjee 2014). Affected people demand equal rights in relocation planning, and they frequently fight against existing land compensation laws and regulations (Morvaridi 2004). Insight into the behavior of individuals or groups of affected people may assist policymakers in designing more acceptable and equitable compensation plans (Kermagoret et al. 2016). However, as one challenge in obtaining such insight, future changes in both individual and collective stakeholders' livelihoods need to be assessed. This assessment requires a practical ex ante assessment tool that can simulate impacts on different stakeholder groups to develop a better understanding of the impacts on affected stakeholders relative to beneficiaries and their sensitivity to varying levels of compensation.

In long-term assessments of water development projects, the existing cost-benefit approaches do not tend to differentiate impacts on different stakeholder groups, making it difficult to reduce the inequality in compensation due to contentious planning, i.e., an undervaluation of assets and a delay in compensation payments (Cernea 2003). Instead of focusing on collective compensation in the cost-benefit approach, a market approach should be adopted in the planning process to assess the willingness of affected individuals to accept the standard payment for resettlement ( $\mathrm{Yu}$ and $\mathrm{Xu}$ 2016). Kunreuther and Easterling (1990) recommended that the behavior of affected individuals should be considered when determining compensation levels. Affected individuals will compare the level of compensation with the expected benefits without the project; then, they will decide to choose the option with greater utility, i.e., to accept the compensation offered or to resist the project (Kunreuther and Easterling 1996).

However, affected individuals have different backgrounds, different levels of willingness to accept, and different levels of resilience to overcome uncertainties. In this article, we model these individuals as "agents" in an agent-based model (ABM). Thus, we often refer to affected farmers as "agents". Factors (in terms of the characteristics of farmers or their farms) that make some affected people more resistant than others or that cause a high level of variability in the willingness to accept certain levels of compensation or risk taking should be duly considered. Popkin (1979) argued that farmers compare alternatives and choose a "higher income and less variance" option for their long-term investment.

Therefore, a long-term ex ante assessment of livelihood impacts that compares the collective and individual benefits among negatively and positively affected agents should be conducted to identify a better compensation policy to limit the inequalities after relocation. Policymakers may deploy scenarios to envision the impacts and the adaptations to the uncertainties of each option considered in decision-making processes. However, most studies limit themselves to collective benefits and impacts (Ghatak and Mookherjee 2014).

Cost-benefit analysis (CBA) is traditionally and commonly used by governments to make decisions about long-term investments in dam and hydropower projects (e.g., Chutubtim 2001; Strzepek et al. 2008). However, in conventional assessments, the focus is on engineering and economic variables, prioritizing the monetary value of collective benefits and omitting the concept of benefit sharing from winners to losers (Morimoto and Hope 2004). This ignorance of equitable benefit sharing and the failure to take disaggregated individual interests into account may cause a lack of participation in cost-benefit 
model development. Scenario assessments should take collective benefits and individual interests into account to provide better insights for the equitable outcomes of dam planning and benefit-sharing options.

Studies on land compensation that illustrate the uncertainties of affected individuals are rare. While other models are able to assess only collective impacts, agent-based modeling adds explanatory power by making it possible to study both collective and individual benefits and impacts with regard to behaviors, uncertainties and other critical indicators.

An ABM can illustrate the uncertainties of agents in the same system (Priya Datta et al. 2007) and can be deployed for ex ante impact assessment for various groups of stakeholders, including minority agents, in water resource planning. This capability can help policymakers understand how a policy alternative affects agents and their behaviors in conflict situations (Akhbari and Grigg 2013). Moreover, presenting ABM results contributes to acknowledging both positive and negative impacts. Therefore, we propose an ABM to assess the ex ante effects of land compensation policy, both individually and collectively, for a better understanding of the impacts on the whole system and to suggest a suitable compensation policy for more equitable outcomes of water resource development projects.

In this study, an ABM for water resourceplanning in southern Thailand is developed and demonstrated (Fig. 1). The aim of this model is to assess the impacts of land compensation policy in a basin development project. The main purpose of this research is to explore how dam construction and compensation policy affect farm income and the share of farmers accepting compensation payments. The ABM approach offers a new tool to assess dam impacts and makes it possible to explicitly model mitigation approaches to prevent negative impacts on affected farmers.

\section{Farmer Behaviors in Water Resource Development Planning}

Farmers consider limitations and options when making a decision regarding new farming activities. A farmer selects the best crops and best practices to maximize yearly and future farm income depending on contextual factors and knowledge about aspects such as the crop yield and the quality of land ( $\mathrm{Ng}$ et al. 2011). With their limitations, farmers may
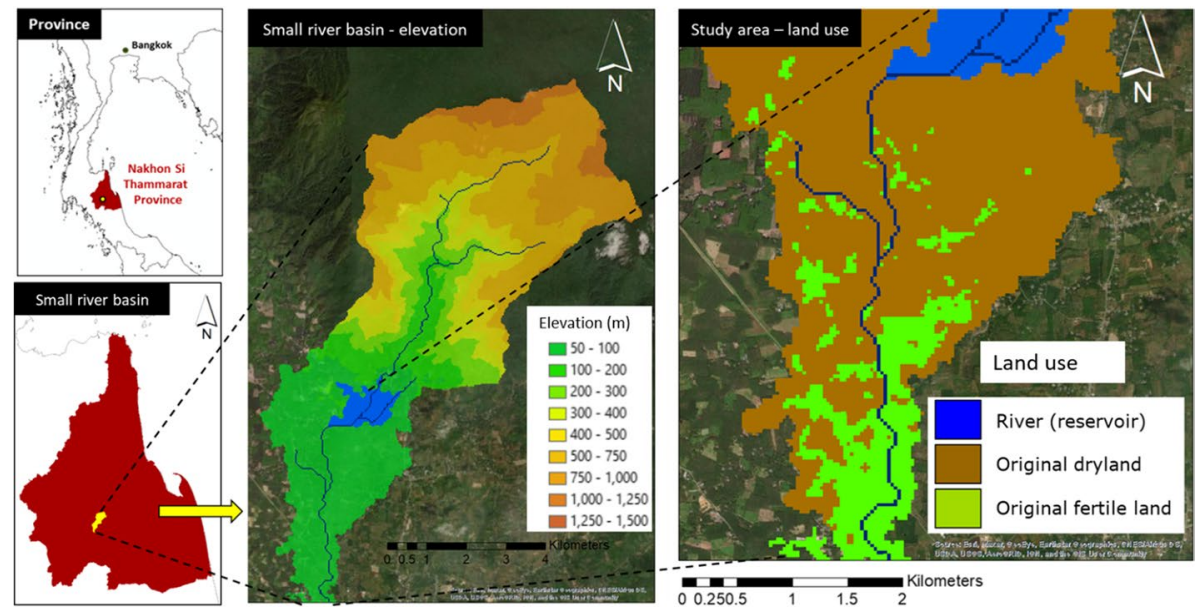

Fig. 1 Setup of a typical ABM environment for water resource development planning in southern Thailand 
review their previous farm income and adapt their farm practices to meet their criteria. Their choices will also be based on expectations for the future (i.e., challenges related to weather, policies, new knowledge, and crop prices) (Becu et al. 2003).

In addition to individual and collective income, other farmer behaviors have been found to influence decisions in response to water limitations (Schlüter and Pahl-Wostl 2007). An optimization decision concept is applied for individual objectives. Individuals are assumed to follow optimization rules to make decisions and improve satisfaction (Berglund 2015). Under the optimization approach, many agents can interact with neighbors and environments to adapt their decisions by regarding other stakeholders' objectives and by allowing stakeholders to cooperate with other stakeholders for their common benefits (Giuliani and Castelletti 2013). This optimization behavior can be applied to facilitate negotiations over conflicting interests among stakeholders; typically, such conflicts concern situations where if one agent wants to work towards meeting one objective, doing so will decrease the effectiveness of the work undertaken by other stakeholders to meet their objectives.

Governments often propose interventions that may affect other stakeholders' livelihoods. For example, Galipeau et al. (2013) investigated the inequality among negatively and positively affected people and compared the differences between resettlers and nonresettlers. They found that negatively affected farmers lose their productive land after resettlement, which affects their standard of living. Consequently, the interactions among stakeholders often change in response to interventions. Therefore, water resource planning requires careful investigation of stakeholder behavior, especially in conflict situations.

In general, a compensation policy may change affected farmers' livelihoods and farm income, and such a policy should be sufficient for farmers to undertake new investment (Ghatak and Mookherjee 2014). Qian (2015) studied the compensation policy for land acquisitions and concluded that affected farmers face challenges of uncertainties related to maintaining their income after resettlement. In this case, monetary compensation is paid for the value of their property, but such compensation is not enough to support their future livelihood or, at the least, to maintain their present income.

In a study by Lebel et al. (2014) on the Sirikit Dam in Thailand, which was built in 1957, the compensation plan was developed without consulting the affected people. In this plan, different types of compensation, such as a pooled lottery allocating distant land and a few facilities, fixed cash compensation for the loss of trees, fixed cash compensation for a household, and compensation in the form of land of a smaller size or lower quality, proved to be inadequate to reach the same standard of living as that expected without the dam. Moreover, this study suggested that compensation should address delays in payment to more quickly resume the standard of living.

\section{Ex Ante Assessment of Farmer Behaviors by Agent-Based Modeling}

A participatory approach to model design attempts to undertake participatory activities to bring stakeholders (including affected stakeholders) together to inform model development (Pahl-Wostl 2002; Singto et al. 2020). The participatory development of scenario modeling approaches can be a powerful tool for proposing solutions for decision-making (Sun and Müller 2013). Correspondingly, a combination of stakeholder perspectives and affected stakeholder reactions can initiate the construction of scenarios for future prediction and for the proposal of alternatives for decision-making. Simulating individual adoption behaviors under uncertain situations in scenarios helps policymakers improve policies (Berger and 
Troost 2014). An ABM is a tool that can facilitate policymakers' comprehension of the impact of changes induced by policy interventions when farmers' decisions, which are the product of several interactions and limitations, are combined in the model to simulate collective impacts (Berger et al. 2007). Moreover, an ABM can simulate an environment and the agents living in the environment as a collective system shaped by individual agents' decisions (Matthews et al. 2007). An ABM can also be used to create a decision framework in which several stakeholders are institutions rather than farmers (Giuliani and Castelletti 2013). Stakeholders can be agents and can react to changes in the environmental system following rules defined by the modelers, with the rules being informed by the real world (Akhbari and Grigg 2013). For example, an ABM was applied to investigate farmers' decisions with a crop model to translate individual farmers' decisions into farm income and costs due to their cropping systems and farming practices ( $\mathrm{Ng}$ et al. 2011).

To evaluate the proposed options for acceptable outcomes in conflicts, an ABM facilitates ex ante assessment to predict responses from stakeholder behavior in response to future interventions under the individual conditions of stakeholders (Le Pira et al. 2017). With these competencies, ABMs can be used in conjunction with other models to conduct ex ante assessments of individual farmers and farmland, including the interactions among stakeholders in adopting policies and the interactions between stakeholders and environments. An ABM helps ex ante to investigate farmers' behaviors under certain limitations and the interactions among stakeholders when individual farmers aim to maximize their farm income. This ability to apply resource limitations makes ABMs superior to other modeling approaches in assessing farmer behavior and resource use. Therefore, an ABM has a high potential to enhance our understanding of the dynamics surrounding dam planning projects and their socioeconomic impacts in water conflict contexts. To date, the limited use of ABMs in the ex ante assessment of dam planning projects may be due to their limited scope in explicitly considering the underlying purposes of policymakers and in taking the interests of all actors into account (Whittington and Smith 2020).

\section{ABM Development for Ex Ante Assessment}

\subsection{Purpose and Setup}

We developed an ABM capable of simulating the impacts of the building of a dam, including the procedures for negotiating compensation, on (accumulated) farmer income and the level of satisfaction. The behaviors of different types of farmers are simulated: with and without a dam planning process and with different amounts of compensation for affected farmers. In addition to the level of compensation, one of the key factors affecting the satisfaction of affected people is the uncertainty experienced during delays in a dam project. Hence, we assessed the sensitivity of the ABM to different periods of dam building caused by delays in the planning process.

The ABM variables and procedures were defined using data available from official documents from relevant governmental organizations and were strengthened with expert and local knowledge to predict or forecast the future (Berger and Troost 2014). Several assumptions were made based on past events, empirical data, and the forecasted probability of future events. The socioeconomic data were based on the Wang Hip dam project environmental impact assessment (EIA) report (RID 2016) and market crop prices (Office of 
Agricultural Economics 2017). Local knowledge was mobilized during workshops, and indepth interviews were conducted over the 2016-2019 period with policymakers and positively and negatively affected farmers (Singto et al. 2018, 2020).

We ran the ABM using NetLogo 6.1.1 software. The model contained a number of stochastic elements, i.e., the distribution of farm size, the crops grown, and the location of farmers, which were initialized in the setup process. Therefore, the ABM should be repeatedly run to calculate an average to analyze the trends in the results (Thiele et al. 2014). We ran simulations for 30 years and analyzed the average and distribution of probabilities of 200 model runs. The default simulation (10\% Y5) was run for a scenario in which, annually, there was a $10 \%$ increase in the offered compensation up to a maximum of 5 years, when the dam would be constructed. Other scenarios were run to explore sensitivities to compensation and the year of construction.

Three types of land were distinguished based on land cover (Globcover 2009), topography (SRTM 2018) and data on current and future irrigable land (RID 2016):

1) Fertile land (green patches), consisting of land close to the river or land benefiting from irrigation (original and future irrigable land), with enough water to grow high-profit crops such as durian.

2) Dryland (brown patches), where most of the patches are far from the river and there is not enough water to grow high-profit crops (original rainfed land). If a dam is constructed, some dryland patches may become irrigated fertile land (green patches).

3) Rivers and inundated areas (blue patches) will increase depending on the amount of rainfall and inundated area.

The ABM applied the distribution (average and standard deviation) from 30 years of rainfall data covering the 1977-2006 period, causing random drought events when the amount of rainfall was below the average (RID 2016).

\subsection{Framework, Agents, and Behaviors}

The ABM simulates the reactions of farmers and other stakeholders to changing environments during the dam planning process and after dam construction for a total of 30 years. Figure 2 presents a flowchart of the main components of the model that are run at an annual time step:

1) Farmer behavior: Farmers decide whether to maintain or plant new tree crops based on trends in market prices, the quality of the land at the location of their plot, the availability of water for irrigation, the availability of funds for investment and the level of certainty of land tenure. Farmers' choices are translated into annual farm income.

2) Satisfaction: Satisfaction is determined based on a comparison of the incomes of farmers in relation to those of neighboring farmers within a search radius. If farmers experience land and water resource issues, this will impact their satisfaction levels, as will relocation in case they need to move to make room for reservoir construction.

3) Dam planning: The numbers of affected and unaffected stakeholders are updated, and a decision regarding dam construction is made or postponed. If the decision is made to construct a dam, in the years following dam construction, negotiations over the compen- 


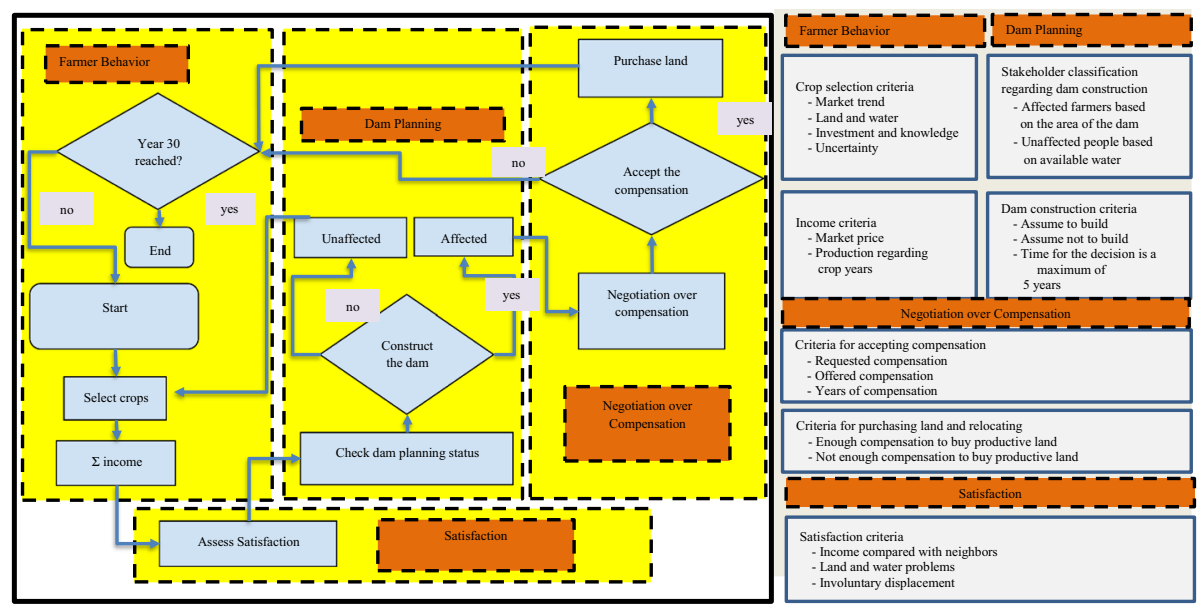

Fig. 2 Flowchart of the ABM visualizing the processes modeled for one agent in one time step and the criteria considered in four model components: farmer behavior, satisfaction, dam planning status, and negotiation over compensation

sation component become active. Otherwise, the next year starts with the determination of farmer behavior.

4) Negotiation over compensation: Affected farmers can either accept this compensation (if they can buy a good, irrigable piece of land using the compensation obtained) or request higher compensation. If they accept the compensation, they will purchase new land and relocate.

\subsubsection{Farmer Behavior}

Farmers can grow three tree crops: para rubber (Hevea brasiliensis), oil palm (Elaeis guineensis) and durian (Durio zibethinus). Which crop they can grow depends on their land and water resources. Each crop comes with an investment cost, a nonproductive period during which the trees produce no returns, and productive periods of a certain duration after which productivity drops. Original dryland farmers involuntarily grow rubber trees in dryland conditions. Some fertile original land farmers may switch to more highly profitable crops such as durian.

Farmers may switch crops (or replant) after passing a threshold age of existing crops (ten years for oil palm and para rubber and twenty years for durian). Based on the current situation, we assumed that $50 \%$ of farmers may potentially change crops, in which case $60 \%$ would grow rubber, $30 \%$ would grow oil palm, and $10 \%$ would grow durian.

\subsubsection{Satisfaction}

Interviews with farmers informed the criteria for the level of satisfaction related to water scarcity and limitations based on previous incomes, farming adaptation, and neighbors' income. The satisfaction scores changed if the elements of satisfaction changed. The 
initial satisfaction was set to 0 . A drought reduces satisfaction by 1 for farmers who are not within the irrigation distance of a river, while satisfaction increases by 1 for all farmers who are near a river. If there is above-average rainfall, satisfaction increases by 1 , and with normal rainfall, satisfaction remains the same. If the income of a farmer is lower than the average of all farmers within his or her neighboring radius, satisfaction decreases by 1 , while if it is higher than the average, satisfaction increases by 1 each year. When the dam is constructed, the satisfaction of farmers who need to relocate decreases by 5 .

\subsubsection{Dam Planning Procedure}

A reservoir is modeled as a potential intervention. It is assumed that irrigation becomes possible by broadening the riparian zone within a reach of two cells from the river (i.e., these cells become productive land). In contrast, if there is no dam, each year, $5 \%$ of farmland far from the river is assumed to turn dry randomly due to increasing water usage for highly profitable crops. The chance of drought in this area was set to $50 \%$. The number of farmers was set to 1000 farmers (comprising 35\% original dryland farmers, $33 \%$ original fertile land farmers, $25 \%$ farmers with land near the river, and $7 \%$ farmers who would be affected if the dam was built) as the default. We assumed that the reservoir would be built in the next five years.

\subsubsection{Compensation for Affected Stakeholders}

The official rate of compensation is dependent on the land title. From interviews with Royal Irrigation Department (RID) officers, the amount of compensation is USD 9766 per hectare or 50,000 baht/rai where one hectare equals 6.25 rai (price assessed by the Land Department) if villagers have land deeds and USD 7813 per hectare without deeds (80\%-90\% of the assessed price). However, the market price of land is generally much higher, approximately USD 48,828 per hectare, and if affected residents wish to buy new farmland, they have to pay this market price. We allowed the land compensation rate to vary, using USD 29,297 per hectare as the default. This amount was assumed to be enough to buy a dryland plot somewhere in the river basin. Compensation negotiations may take several years. Each year during the negotiation, the compensation level was assumed to increase by $10 \%$ (based on the interviews with the RID officers). Farmers keep receiving farm income from their land as long as they have not relocated. Upon relocation, affected farmers will change crops based on their expectations and limitations.

\section{Results}

\subsection{Behaviors of Individual Affected Farmers}

The ABM simulates the decisions of all specified individual farmers. To illustrate this functioning, we randomly selected three individual affected farmers for the first run of the ABM in the default scenario (10\%Y5). The three individual farmers (\#74, \#580, and \#666) accepted the proposed compensation in different years, faced different limitations 
in selecting crops, and showed a variable evolution of satisfaction due to the changes they faced (Fig. 3 and Supplementary Table S1).

The above examples show that the responses of individual farmers to crop prices, water and land availability, and compensation are specific to each affected farmer. The speed of the decision to accept compensation tended to increase their future income and satisfaction. This result implies that combining behaviors (making a quick decision to move, investing right after receiving compensation, and having the ability to change crops) can mutually reinforce affected people's chances of improving their income and satisfaction after displacement.

\subsection{The Predicted Farm Income}

Figure 4a shows the accumulated income for each land type per hectare in a default scenario without and with dam construction. The performance of affected farmers is similar

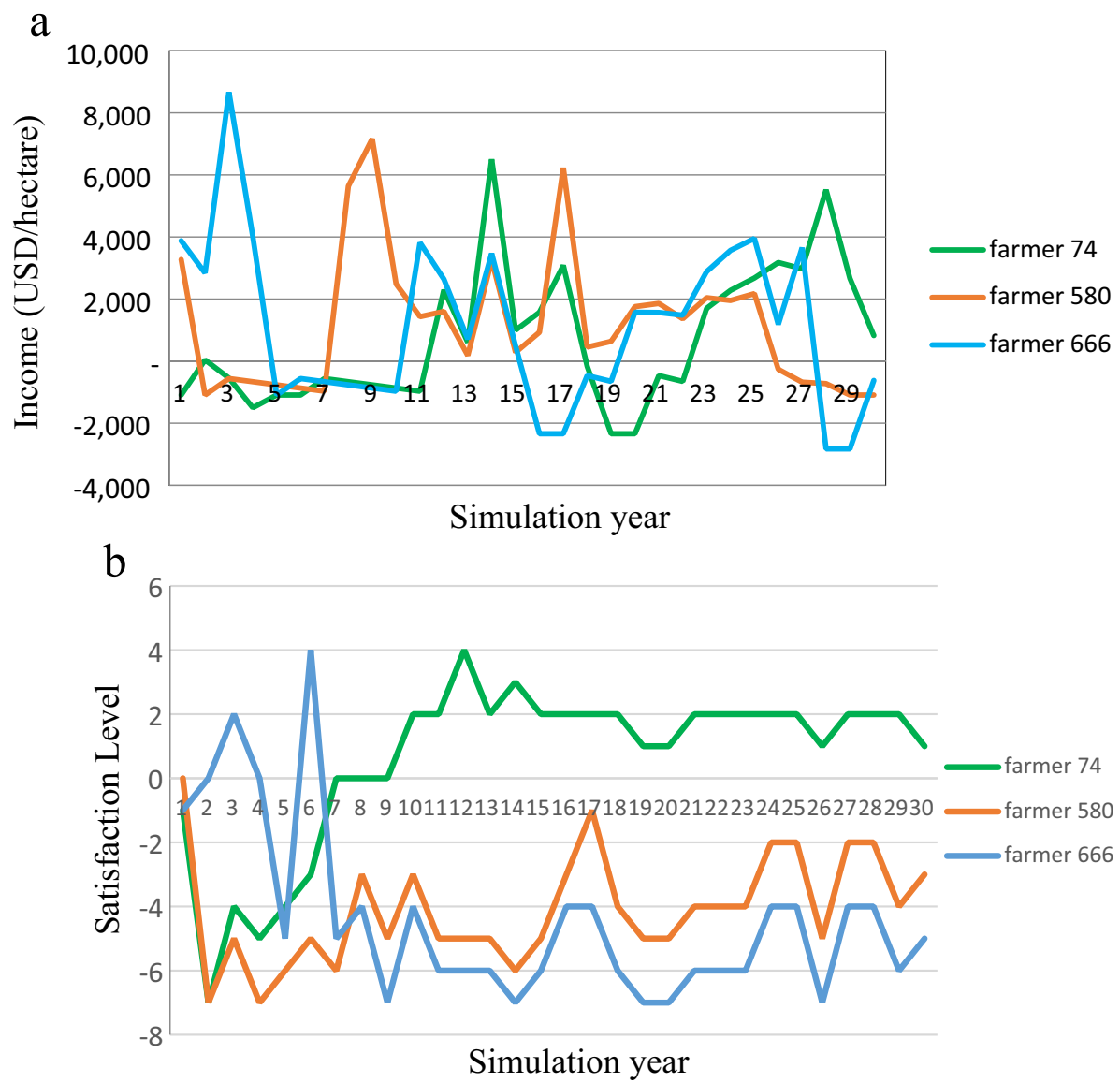

Fig. 3 Farming behavior of individual affected farmers: a evolution of income; $\mathbf{b}$ evolution of the satisfaction level 
to that of farmers on original productive land. Affected farmers will have more chances to select more highly profitable crops and receive a good farm income due to living on productive land from which they do not need to be displaced.

Under the with-dam scenario, farmers on productive land will have greater income. Dryland farmers continue to have the lowest income in the long run. Affected farmers will experience a period of low or even negative income during the years of resettlement but will catch up with the average level of farmers towards the end of the simulation (Supplementary Figure S1). However, their income might increase if the irrigated area gradually expands after the construction of the dam (see Sect. 5.1).

The average income after 30 years will be higher with dam construction. Therefore, transforming drylands into irrigated land can assist dryland farmers in increasing their farm income. However, potentially affected farmers may have problems finding new productive land and financing crop investment, which explains why they obtain less income than productive land farmers.

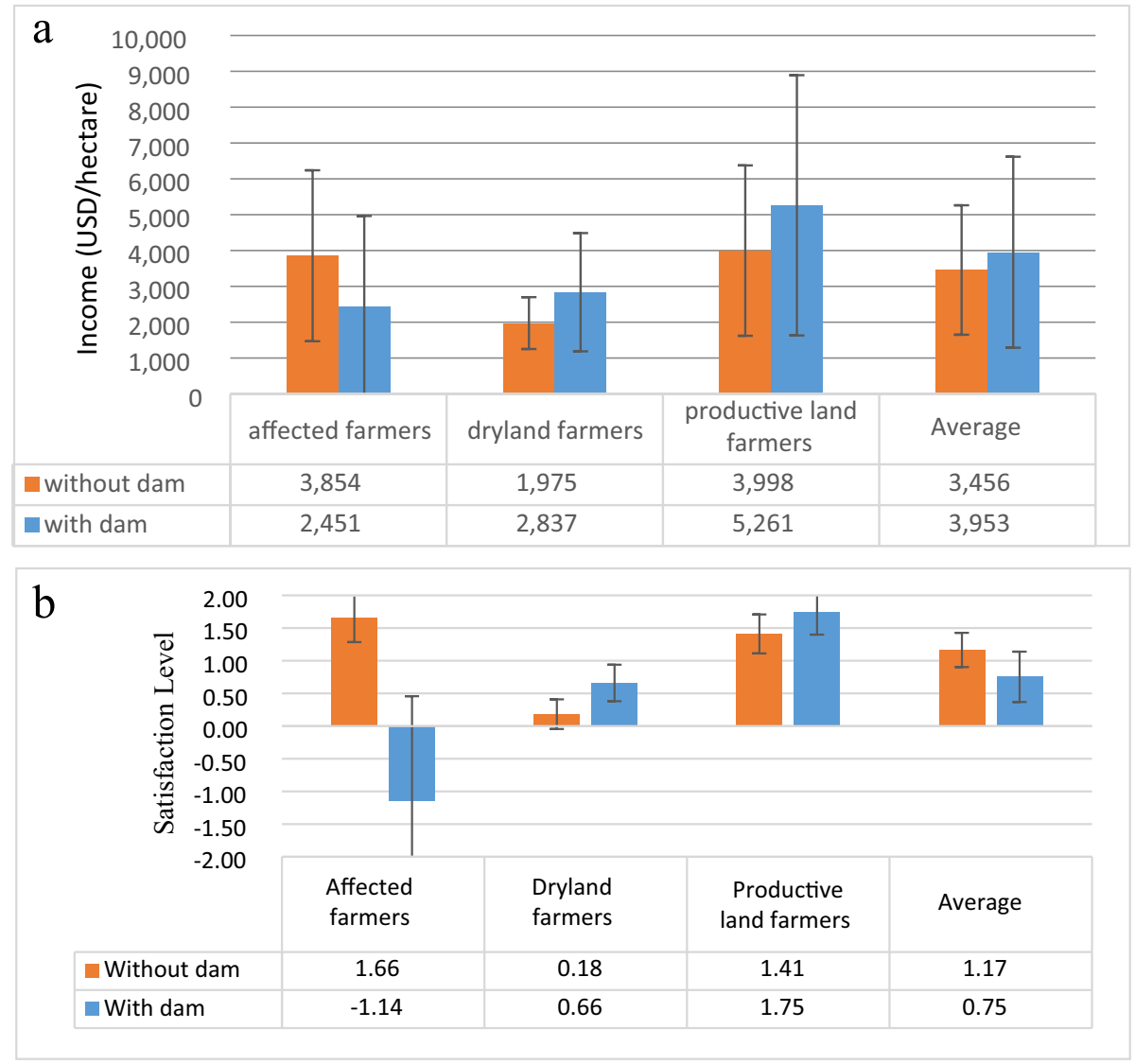

Fig. 4 Comparison of $\mathbf{a}$ the accumulated farm income and $\mathbf{b}$ the satisfaction of different types of farmers over 30 years. The error bars represent the standard deviations from 200 simulations for the default $10 \%$ Y 5 scenario 


\subsection{Predicted Satisfaction}

Farmers situated far from the river living on drylands have the lowest (0.18) satisfaction without a dam (Fig. 4b). This limitation causes below-average incomes and little opportunity to grow highly profitable crops. In contrast, affected farmers do not need to be displaced, and living near the river on productive land will maintain their satisfaction level.

In contrast, in the case in which the dam is constructed, affected farmers show an extreme decrease in satisfaction when dam construction is begun (the satisfaction level drops to a low of -6 ; see Supplementary Figure S1). The scenario shows the lowest satisfaction of affected farmers, especially at the start of resettlement. Satisfaction increases over time due to fewer limitations in accessing water and growing more profitable crops. Interestingly, the increase in satisfaction will take longer than 10 years, and uncertainty over access to irrigated land and future income remains. Therefore, this scenario may cause resistance to dam construction.

The average satisfaction levels after 30 years for the two scenarios show that dryland farmers and productive land farmers will be more satisfied with the dam than without the dam. Overall, the dam will increase farmers' accumulated satisfaction living in dryland and productive land, whereas affected farmers will become more dissatisfied (1.66 to -1.14) (Fig. 4b).

\subsection{Validation of the ABM}

Model validation with regard to the ability of the model to present and compare the income and satisfaction of different types of farmers was performed on 13 November 2018 by arranging a focus group discussion with both planners from the central RID and practitioners from the local RID office and RID participation officers responsible for planning participation in the project. Moreover, a senior representative of farmers and a lecturer on farming economics living in the province participated to validate the results on farm income and the impacts of compensation.

The policymakers involved in the focus group discussion about the ABM results agreed that they received more knowledge of the impacts of the planned water resource development project for positively and negatively affected farmers. However, due to the strong conflicts, they were skeptical that the knowledge from the model could be discussed in participatory meetings with both positively and negatively affected farmers to consult and adjust the planning for the negatively affected farmers. Moreover, satisfaction was considered by the policymakers to be the most challenging variable to measure, and a higher overall satisfaction level as determined by the model does not guarantee that the dam will be constructed.

In summary, the advantage of this $\mathrm{ABM}$ is that it can show the changes in accumulated income during the different years of dam implementation. The ABM helps to consider the impacts of the dam intervention. However, it is difficult to apply the results to decide whether or not the dam should be constructed. It is also difficult to refer to the results of the model to negotiate the compensation for farmers. Finally, the use of the ABM to consult and co-design dam projects with stakeholders is challenging due to existing laws and regulations concerning dam construction and compensation. 


\subsection{Sensitivity Analysis of Affected Farmers}

A sensitivity analysis was performed to quantify the effect of different negotiation modalities, considering different incremental levels of compensation and lengths of the negotiation period in the following combinations (Fig. 5):

- Default (10\%Y5): + 10\% increase in compensation offered per year for 5 years

- Alternative 20\% Y $4:+20 \%$ increase in compensation offered per year for 4 years

- Alternative 30\% Y3: + 30\% increase in compensation offered per year for 3 years

- Alternative 0\%Y3:+0\% increase in compensation offered per year for 3 years

The ABM was run 200 times for each scenario. The initial compensation price was kept constant in all scenarios based on a proposed land compensation price of USD 29,297 per hectare plus compensation for mature trees on farmers' land (see Sects. 5.1 and 5.2).

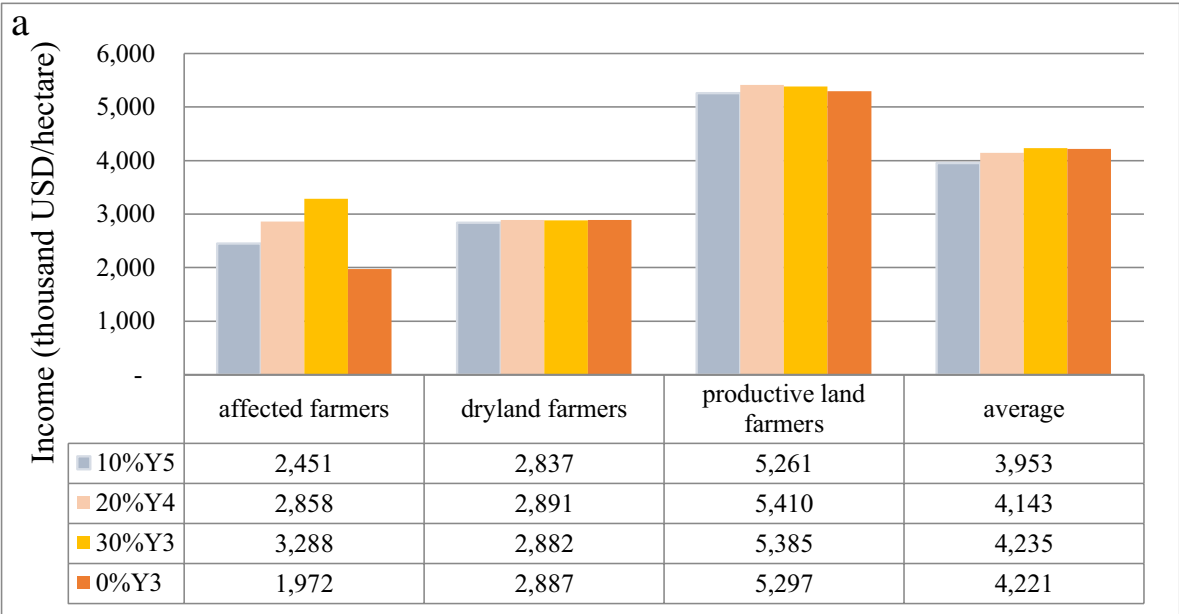

\begin{tabular}{|c|c|c|c|c|}
\hline \\
\hline & & & & \\
\hline \multirow{4}{*}{$\begin{array}{r}1.00 \\
0.00 \\
-1.00 \\
-2.00\end{array}$} & & & & \\
\hline & & & & \\
\hline & & & & \\
\hline & $\begin{array}{l}\text { affected } \\
\text { farmers }\end{array}$ & $\begin{array}{l}\text { dryland } \\
\text { farmers }\end{array}$ & $\begin{array}{l}\text { productive } \\
\text { land farmers }\end{array}$ & average \\
\hline 10\%Y5 & -1.15 & 0.66 & 1.60 & 1.08 \\
\hline $20 \% Y 4$ & -0.87 & 0.69 & 1.63 & 1.13 \\
\hline 30\%Y3 & -0.74 & 0.68 & 1.64 & 1.14 \\
\hline 0\%Y3 & -1.37 & 0.73 & 1.66 & 1.12 \\
\hline
\end{tabular}

Fig. 5 a Average 30-year income and b level of satisfaction for different types of farmers under four compensation scenarios 
During the negotiation period, affected farmers continued to receive income from their farm production until they accepted compensation and moved to a new plot.

Alternative $2(30 \% \mathrm{Y} 3)$ provides the highest income to affected farmers (USD 3.29 million per hectare). This modality also leads to the highest income for dryland farmers (USD 2.88 million) and farmers overall (USD 4.24 million). Clearly, the cumulative income of affected farmers is far more sensitive to the negotiation modalities than that of unaffected farmers.

The negotiation modality of increasing compensation by $30 \%$ each year for 3 years (30\% Y3) also provides the highest average level of overall satisfaction, 1.14, which is higher than the default (10\% Y5), 1.08. In addition, the $30 \% \mathrm{Y} 3$ modality generates the highest level of satisfaction for affected farmers $(-0.74)$. This option, however, does not provide the highest satisfaction for dryland farmers and productive land farmers, for whom the $0 \% \mathrm{Y} 3$ modality is the best. Nonetheless, for these categories of farmers, the differences are negligible, whereas affected farmers respond strongly to the negotiation modalities.

This sensitivity analysis indicates that increasing compensation and shortening the negotiation period enable the maximization of income for all types of farmers. Moreover, by increasing the compensation levels, the speed of the negotiation process can be accelerated while positively impacting affected farmers' satisfaction scores. Without higher compensation, quick dam construction will be preferred by dryland and productive land farmers, but such construction will come at the expense of affected farmers, considerably exacerbating their dissatisfaction.

\section{Discussion}

This paper presents a case where an ABM is compiled with farmer behaviors and the water resource planning policy of a river basin to comprehend the impacts of changing the environments of agricultural activities through the construction of a reservoir and the compensation of affected farmers. The ABM is found to be helpful in assessing the economic and social implications for farmers, both individually and collectively.

At the collective level, the outcomes of the ABM resemble those of studies using common CBA approaches. Irrigation makes it possible to grow more profitable crops and expand the cropping area (e.g., Strzepek et al. 2008; Manikowski and Strapasson 2016). From a financial perspective, given that beneficiaries outnumber negatively affected people, quick reservoir construction is key to having the best collective outcome. Our ABM shows that periods of stagnation in decisions on dam construction introduce uncertainty for farmers who may thus postpone decisions or be forced to make suboptimal decisions given the context and constraints faced at the time, resulting in a lock-in that reduces profitability if the reservoir materializes at a later moment. The ABM focuses on agronomic aspects and hence is not concerned with the externalities of reservoir projects, which could have important negative implications (cf. Manikowski and Strapasson 2016).

In addition to considering collective outcomes, this study considers the variation in individual outcomes and provides some examples of impacts on individual affected farmers facing different limitations, which may be very different from the collective benefits (Cernea 2003). With the low amount of compensation, affected farmers lose the opportunity to receive the income that they currently have and will likely continue to enjoy if no dam is constructed, nor can they sustain a new settlement. Therefore, this study argues that 
the compensation valuation in existing CBAs should be improved (Cernea 2003; Yu and $\mathrm{Xu}$ 2016).

Although ABMs are not necessarily suitable for, or intended to simulate the effects on individual agents (Schreinemachers et al. 2010), the examples of the individual affected farmers investigated align with Rai (2007), who found unequal compensation for individual farmers in a dam study. While Ghatak and Mookherjee (2014) argue that compensation is acceptable when it supports investments by affected farmers, our investigation of individual farmers shows that a low mandatory compensation policy is insufficient for new investment in productive land and the restoration of income and satisfaction after displacement. Therefore, this study echoes Lebel et al. (2014), who concluded that low compensation levels brought lower income and low satisfaction to affected people and obstructed the dam policy.

In the sensitivity analysis, different periods of the start of dam construction also affected the overall compensation and restoration of the incomes of individual affected farmers. Individuals still harvest from their previous farmland after they accept the compensation until dam construction begins. Therefore, a delay in construction might increase the level of overall compensation plus farm income from their existing land. Even though it seems beneficial to delay the project, doing so would be an illusion for affected farmers. A delay in starting construction would also delay the first farm income from new investment. In addition, the later acceptance of compensation would make affected farmers unable to afford the more expensive price of new land and obtain land in the first place, as less land would be available. Therefore, the time of resettlement and the compensation mechanism should be taken into account. Furthermore, improving the compensation mechanism can help mitigate the resistance of protesters (Morvaridi 2004).

Underpinning the ABM is a decision-making framework based on theories of optimization of farmer decisions as well as social benchmarking through satisfaction scores. Whereas the optimization of farm income subject to resource constraints is widely implemented as a decision strategy in modeling studies, its success is rarely measured in relative terms through social benchmarking (see, e.g., Mialhe et al. 2012). However, levels of compensation that disregard equity considerations and future income based on limitations and optimization theories can cause strong conflicts. Some scenarios deliver benefits to dryland farmers and others but leave negatively affected farmers to suffer more than 20 years.

An enhanced understanding of the whole irrigation system can provide new knowledge and allow negotiation to mitigate the negative impacts involved in water resource planning (Berger et al. 2007). It has been postulated that ABMs can be used in a conflict situation (Akhbari and Grigg 2013). The perspectives of affected farmers involuntarily resettling in other areas were investigated. The mandatory laws and regulations compensated only for damaged property such as land, crops, and buildings. However, the displacement of affected farmers needs fair compensation for farmland acquisition and the value of crops. In this regard, the compensation offered by government rules causes unfair benefits and the dissatisfaction of affected farmers.

Moreover, investigating long-term dam construction and compensation outcomes is required because a better understanding of the adverse impacts on affected people facilitates an equitable distribution to affected farmers in early-stage planning (Lebel et al. 2014). Although ex ante assessment may not be practical for finding an optimal value of compensation in a situation if stakeholder elicitation is limited (Rakotonarivo et al. 2017), we argue that a suitable combination of earlier dam construction and increased compensation can support decision-making to decrease the inequality among farmers in water resource development. In line with Giuliani and Castelletti (2013), several stakeholders can 
be engaged in an $\mathrm{ABM}$ to support decision-making in a conflict situation. Therefore, this study shows that an ABM is an effective tool for the ex ante assessment of farmers' income and compensation for negative impacts, using variations in negotiation periods to mitigate impacts and to reduce the inequality among affected people.

Two groups of agents can implement the policy implications of these findings. Policymakers can apply ex ante ABM assessment as a practical tool to improve the traditional CBA model to assess individual impacts for improving the equity in benefit sharing through negotiation and the timing when a decision is made. Most importantly, rather than a conventional method of dialogue, facilitators of stakeholder engagement can apply the framework and model to support arguments, hence creating more tangible results to forecast compared to intangible dialogues in the negotiation process. Therefore, this ex ante ABM research can help policymakers understand affected stakeholders' concerns about the impacts of a dam project and make more suitable decisions to reduce the likelihood of conflicts.

\section{Conclusion}

This study fills a gap in scientific research by assessing the impacts of reservoirs on individual farmers, as opposed to previous studies that conducted only collective assessments of farmer groups. Such assessment required a new approach to modeling water resource development conflicts that is capable of simulating changes in environments, farm income, and satisfaction under the impact of dam construction and compensation policy. Therefore, an $\mathrm{ABM}$ is presented as a tool for the ex ante assessment of the impacts of interventions by simulating farmer behaviors under resource limitations in real-world environments. The agents are farmers who benefit and negatively affected farmers with conflicting interests in the dam planning process. Compensation is added as the crucial process to manage/resolve conflicts among stakeholders and policymakers in decision-making to implement the dam project. An ex ante assessment is presented for predicting farm income and satisfaction under scenarios with different durations of starting dam construction and the overall compensation level. The discussion focuses on the collective and individual impacts based on these different scenarios.

It is necessary to explore a practical technique that can combine multiple disciplines and stakeholder interests. In the participatory planning process, dialogues are not sufficient to present the impacts on stakeholders. Policymakers need a clearer understanding of the implications of planned interventions for stakeholders' livelihoods. Affected stakeholders often request compensation for specific impacts they will suffer, which are pivotal criteria for their contribution to the project. Therefore, policymakers need a scenario analysis to illustrate the effects of policy alternatives.

A scenario study with an ABM that compares the impacts on affected farmers with overall farmers in the next 30 years shows the inequality of the compensation policy by demonstrating that negatively affected farmers lose their land and income, whereas other farmers gain more benefits if the dam is built. The compensation is too low to buy new productive land to grow crops that are as equally highly profitable as those they could grow if no dam were constructed. The conditions of being able to buy only less productive farmland and experiencing less income during the new crop plantation for 3-7 years cause them to suffer for more than a decade, causing dissatisfaction. Moreover, 30 years is regarded as 
a long period for affected stakeholders to restore their livelihood after replacement. These conditions will fuel strong opposition to the dam.

This ex ante impact assessment implies that the dam will increase the collective farm income of farmers in the next 30 years. Most farmers will have more opportunities to select crops for drylands and benefit from a more stable availability of water for productive land. However, affected farmers with low compensation will suffer the opposite results. Opposition can be a practical way for affected farmers to gain more compensation. However, if the negotiation period is too long, the accumulated income will decrease, despite higher overall compensation due to the delay in new land investment. The ex ante impact assessment using agent-based modeling presented here shows just how much dissatisfaction can be avoided in this way. Therefore, the government should improve the assessment method to speed up new land investment by using future income if there is no dam as the reference level for determining compensation instead of estimating based on the present value of existing land. The ABM appears to be a useful tool for exploring a multitude of future income scenarios and the variations in outcomes for positively and negatively affected farmers.

Supplementary Information The online version contains supplementary material available at https://doi. org/10.1007/s11269-021-02771-0.

Authors Contributions The first author collected the data and wrote the paper; Martijn de Vries assisted in writing the code for the modelling; Gert Jan Hofstede guided and solved the modelling problems; Luuk Fleskens reviewed and improved the manuscript.

Funding the Royal Thai Government Scholarship Program (offered by OCSC).

Data Availability Yes.

\section{Declarations}

Ethical Approval All work is compliance with Ethical Standards.

Consent to Participate Authors give their permission.

Consent to Publish Authors give their permission.

Competing Interests The authors declare no competing interests.

Open Access This article is licensed under a Creative Commons Attribution 4.0 International License, which permits use, sharing, adaptation, distribution and reproduction in any medium or format, as long as you give appropriate credit to the original author(s) and the source, provide a link to the Creative Commons licence, and indicate if changes were made. The images or other third party material in this article are included in the article's Creative Commons licence, unless indicated otherwise in a credit line to the material. If material is not included in the article's Creative Commons licence and your intended use is not permitted by statutory regulation or exceeds the permitted use, you will need to obtain permission directly from the copyright holder. To view a copy of this licence, visit http://creativecommons.org/licenses/by/4.0/.

\section{References}

Akhbari M, Grigg NS (2013) A framework for an agent-based model to manage water resources conflicts. Water Resour Manag 27(11):4039-4052

Becu N, Perez P, Walker A, Barreteau O, Le Page C (2003) Agent based simulation of a small catchment water management in northern Thailand: description of the CATCHSCAPE model. Ecol Model 170(2-3):319-331 
Berger T, Troost C (2014) Agent-based modelling of climate adaptation and mitigation options in agriculture. J Agric Econ 65(2):323-348

Berger T, Birner R, Mccarthy N, DíAz J, Wittmer H (2007) Capturing the complexity of water uses and water users within a multi-agent framework. Water Resour Manag 21(1):129-148

Berglund EZ (2015) Using agent-based modeling for water resources planning and management. J Water Resour Plan Manag 141(11):04015025

Cernea MM (2003) For a new economics of resettlement: a sociological critique of the compensation principle. Int Soc Sci J 55(175):37-45

Chutubtim P (2001) Guidelines for conducting extended cost-benefit analysis of dam projects in Thailand. EEPSEA, Singapore

Galipeau BA, Ingman M, Tilt B (2013) Dam-induced displacement and agricultural livelihoods in China’s Mekong Basin. Hum Ecol 41(3):437-446

Ghatak M, Mookherjee D (2014) Land acquisition for industrialization and compensation of displaced farmers. J Dev Econ 110:303-312

Giuliani M, Castelletti A (2013) Assessing the value of cooperation and information exchange in large water resources systems by agent-based optimization. Water Resour Res 49(7):3912-3926

Globcover (2009) Global land cover map for 2009 (GlobCover 2009). ESA \& UCL. http://due.esrin.esa. int/globcover/. Accessed Dec 2020

Kermagoret C, Levrel H, Carlier A, Dachary-Bernard J (2016) Individual preferences regarding environmental offset and welfare compensation: a choice experiment application to an offshore wind farm project. Ecol Econ 129:230-240

Kunreuther H, Easterling D (1990) Are risk-benefit tradeoffs possible in siting hazardous facilities? Am Econ Rev 80(2):252-256

Kunreuther H, Easterling D (1996) The role of compensation in siting hazardous facilities. J Policy Anal Manag 15(4):601-622

Le Pira M, Marcucci E, Gatta V, Inturri G, Ignaccolo M, Pluchino A (2017) Integrating discrete choice models and agent-based models for ex-ante evaluation of stakeholder policy acceptability in urban freight transport. Res Transp Econ 64:13-25

Lebel L, Lebel P, Chitmanat C, Sriyasak P (2014) Benefit sharing from hydropower watersheds: rationales, practices, and potential. Water Res Rural Dev 4:12-28

Manikowski S, Strapasson A (2016) Sustainability assessment of large irrigation dams in Senegal: a cost-benefit analysis for the Senegal River Valley. Front Environ Sci 4:18

Matthews RB, Gilbert NG, Roach A, Polhill JG, Gotts NM (2007) Agent-based land-use models: a review of applications. Landsc Ecol 22(10):1447-1459

Mialhe F, Becu N, Gunnell Y (2012) An agent-based model for analyzing land use dynamics in response to farmer behaviour and environmental change in the Pampanga delta (Philippines). Agr Ecosyst Environ 161:55-69

Morimoto R, Hope C (2004) Applying a cost-benefit analysis model to the Three Gorges project in China. Impact Assess Proj Apprais 22(3):205-220

Morvaridi B (2004) Resettlement, rights to development and the Ilisu Dam, Turkey. Dev Chang 35(4):719-741

Ng TL, Eheart JW, Cai X, Braden JB (2011) An agent-based model of farmer decision-making and water quality impacts at the watershed scale under markets for carbon allowances and a second-generation biofuel crop. Water Resour Res 47(9)

Office of Agricultural Economics (OAE) (2017) Agricultural Statistics of Thailand 2016. Ministry of Agriculture and Cooperative, Office of Agricultural Economics, Bangkok, Thailand

Pahl-Wostl C (2002) Towards sustainability in the water sector-the importance of human actors and processes of social learning. Aquat Sci 64(4):394-411

Popkin SL (1979) The rational peasant: the political economy of rural society in Vietnam. Univ of California Press, Berkeley

Priya Datta P, Christopher M, Allen P (2007) Agent-based modelling of complex production/distribution systems to improve resilience. Int J Log Res Appl 10(3):187-203

Qian Z (2015) Land acquisition compensation in post-reform China: evolution, structure and challenges in Hangzhou. Land Use Policy 46:250-257

Rai K (2007) The dynamics of social inequality in the Kali Gandaki 'A'dam project in Nepal: the politics of patronage. Hydro Nepal: Journal of Water, Energy and Environment 1:22-28

Rakotonarivo OS, Jacobsen JB, Larsen HO, Jones JP, Nielsen MR, Ramamonjisoa BS, ... Hockley N (2017) Qualitative and quantitative evidence on the true local welfare costs of forest conservation in Madagascar: are discrete choice experiments a valid ex ante tool? World Dev 94:478-491 
RID (2016) Environmental Impact Assessment EIA Report; Wang Hip project, Nakhon Si Thammarat Province t; (RID Office of Project Management), Ed. Royal Irrigation Department, Bangkok

Schlüter M, Pahl-Wostl C (2007) Mechanisms of resilience in common-pool resource management systems: an agent-based model of water use in a river basin. Ecol Soc 12(2):4

Schreinemachers P, Potchanasin C, Berger T, Roygrong S (2010) Agent-based modeling for ex ante assessment of tree crop innovations: Litchis in northern Thailand. Agric Econ 41(6):519-536

Singto C, Fleskens L, Vos J (2018) Institutionalizing participation in water resource development: bottomup and top-down practices in southern Thailand. Water 10(6):781

Singto C, Fleskens L, Vos J, Quinn C (2020) Applying Bayesian belief networks (BBNs) with stakeholders to explore and codesign options for water resource interventions. Sustainable Water Resources Management 6(2):1-17

SRTM (2018) Shuttle Radar Topography Mission 1 Arc-Second Global (Digital Object Identifier (DOI) number: https://doi.org/10.5066/F7PR7TFT

Strzepek KM, Yohe GW, Tol RS, Rosegrant MW (2008) The value of the high Aswan Dam to the Egyptian economy. Ecol Econ 66(1):117-126

Sun Z, Müller D (2013) A framework for modeling payments for ecosystem services with agent-based models, Bayesian belief networks and opinion dynamics models. Environ Model Softw 45:15-28

Thiele JC, Kurth W, Grimm V (2014) Facilitating parameter estimation and sensitivity analysis of agentbased models: a cookbook using NetLogo and R. J ArtifSocSoc Simul 17(3):11

Whittington D, Smith VK (2020) The ex-ante economic analysis of investments in large dams: a brief history. FutureDAMS working paper 009. The University of Manchester, Manchester

Yu B, Xu L (2016) Review of ecological compensation in hydropower development. Renew Sustain Energy Rev 55:729-738

Publisher's Note Springer Nature remains neutral with regard to jurisdictional claims in published maps and institutional affiliations.

\section{Authors and Affiliations}

\section{Chakaphon Singto $^{1}$ (D) Martijn de Vries $^{2} \cdot$ Gert Jan Hofstede $^{2} \cdot$ Luuk Fleskens $^{1}$}

Martijn de Vries

martijndevriesgrou@outlook.com

Gert Jan Hofstede

gertjan.hofstede@wur.nl

Luuk Fleskens

luuk.fleskens@wur.nl

1 Soil Physics and Land Management, Wageningen University \& Research, Droevendaalsesteeg 3, 6708 PB Wageningen, the Netherlands

2 Information Technology, Wageningen University \& Research, Hollandseweg 1, 6706 KN Wageningen, the Netherlands 